\title{
A Carbohydrate-Containing Synthetic Polymer Obtained from $N$-p-Vinylbenzyl-D-gluconamide
}

\author{
Kazukiyo KobaYASHI, Hiroshi Sumitomo, and Yoshimitsu INA \\ Faculty of Agriculture, Nagoya University, \\ Chikusa, Nagoya 464, Japan
}

(Received May 20, 1983)

\begin{abstract}
A polymer having carbohydrates as pendant groups was prepared by a coupling reaction between $p$-vinylbenzylamine and D-glucono-1,5-lactone followed by polymerization of the resulting $N$-p-vinylbenzyl-D-gluconamide. The polymer was water-soluble and bound strongly methyl orange and magnesium 1-anilino-8-naphthalenesulfonate (ANS) in water. The binding properties and polymer conformation in water are discussed.

KEY WORDS Carbohydrate-Containing Polymer / Water-Soluble Polymer / Binding of Organic Solute / $p$-Vinylbenzylamine / D-Glucono-1,5-lactone / $N$-p-Vinylbenzyl-D-gluconamide /
\end{abstract}

Synthetic polymers containing carbohydrates are attracting an increasing amount of attention since they may possess unusual properties of carbohydrates. They are composites of petrochemicals and biomass chemicals and thus may have application in the effective utilization of natural resources. In this paper, a new polymer 2 has been synthesized according to Scheme I.

$N$-p-Vinylbenzyl-D-gluconamide (1) was prepared by a coupling reaction between D-glucono-1,5lactone and $p$-vinylbenzylamine. The procedure, originally developed by Williams et al ${ }^{1,2}$ for the synthesis of model glycolipids, has several advantages in preparing vinyl compounds containing
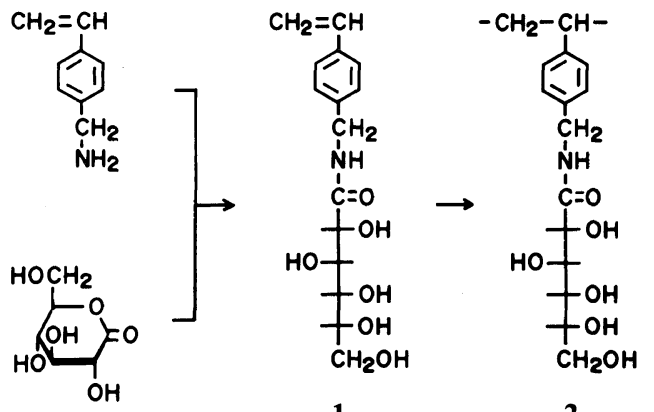

2 carbohydrate moieties. The reaction is simple and the carbohydrate needs no protection of hydroxyl groups; only mixing of the two reactants in refluxing methanol gives the product in a quantitative yield. One of the reactants is a lactone readily prepared by oxidation of a reducing sugar. Therefore, the procedure is applicable to any mono-, oligo- and polysaccharides having reducing sugar ends. On the other hand, preliminary experiments showed that Dglucono-1,5-lactone reacted with benzylamine much faster than with aniline. Consequently, $p$-vinylbenzylamine was used. $p$-Vinylbenzylamine was prepared from $p$-vinylbenzyl chloride according to the Gabriel synthesis.

Scheme I. Synthesis and polymerization of<smiles>CCC(C)c1cccc(COC23O[C@H](O)[C@@H](C(O)[C@H]2O)C3(O)CO)c1</smiles>
$N$-p-vinylbenzyl-D-gluconamide (1). 
Radical polymerization of $\mathbf{1}$ yielded the watersoluble polymer 2 . In the latter half of this paper, it is shown that $\mathbf{2}$ has a strong affinity for methyl orange and magnesium 1-anilino-8-naphthalenesulfonate (ANS) in water. We previously reported the binding of these organic solutes to polymer 3. ${ }^{3-5} 2$ and 3 each have amphiphilic structural units consisting of hydrophilic carbohydrate moieties and hydrophobic vinylbenzyl groups. In polymer 3 , the oxygen in position 3 of the pyranose ring is attached to the vinylbenzyl group by an ether linkage. A mixture of meta- and para-isomers was prepared. In contrast, the carbohydrate of polymer $\mathbf{2}$ is an open chain and connected to the para-substituted vinylbenzyl group by an amide linkage. The binding properties of 2 and 3 are compared.

\section{EXPERIMENTAL}

\section{General}

NMR spectra were recorded on Japan Electron Optics Laboratory JNM-MH-100 NMR and JNMFX-100 Fourier transform NMR spectrometers. Tetramethylsilane was used as the internal standard in deuteriochloroform and in dimethyl sulfoxide- $d_{6}$ $\left(\mathrm{Me}_{2} \mathrm{SO}-d_{6}\right)$, and as an external standard in deuterium oxide. Optical rotations were determined with a JASCO DIP-181 digital polarimeter using a 1-dm cell. Viscosities were measured in Ubbelohde viscometers at $25^{\circ} \mathrm{C}$. The binding of methyl orange and ANS was measured at room temperature with a JASCO UVIDEC 505 digital double-beam spectrophotometer and a JASCO FP-550 spectrofluorometer. ${ }^{3,4}$

\section{$N$-p-Vinylbenzylphthalimide}

$p$-Vinylbenzyl chloride was prepared from $\beta$ phenylethyl alcohol using $\beta$-phenylethyl bromide and $p$ - $\left(\beta\right.$-bromoethyl)benzyl chloride. ${ }^{6}$ A mixture of $p$-vinylbenzyl chloride $(15.3 \mathrm{~g}, 0.10 \mathrm{~mol})$ and potassium phthalimide $(18.5 \mathrm{~g}, 0.10 \mathrm{~mol})$ was dissolved in $50 \mathrm{ml}$ of $N, N$-dimethylformamide (DMF) and heated at $50^{\circ} \mathrm{C}$ for $4 \mathrm{hr}$. DMF was removed in a vacuum evaporator, and the residue was dissolved in chloroform. The solution was washed with aqueous $0.2 \mathrm{~N}$ sodium hydroxide solution and then with water, and concentrated. The product was crystallized from methanol. Yield, $22.2 \mathrm{~g}(84 \%)$. Recrystallization from methanol gave pure crystals of $\mathrm{mp} 107-108^{\circ} \mathrm{C}$. Calcd for $\mathrm{C}_{17} \mathrm{H}_{13} \mathrm{NO}_{2}$ : .C, $77.55 \%$; H, $4.98 \%$; N, 5.32\%. Found: C, $77.47 \%$; H, $5.00 \% ; \mathrm{N}, 5.28 \%$.

\section{p-Vinylbenzylamine}

A solution of $80 \%$ pure hydrazine hydrate $(6.6 \mathrm{~g}$, $0.105 \mathrm{~mol})$ in ethanol $(10 \mathrm{ml})$ was added to a refluxing solution of $N$-p-vinylbenzylphthalimide $(18.4 \mathrm{~g}$, $0.07 \mathrm{~mol})$ in ethanol $(50 \mathrm{ml})$. Immediately, a white stiff crystalline mass started to precipitate. Refluxing and vigorous mechanical stirring were continued for $90 \mathrm{~min}$. The precipitate was filtered and the filtrate was concentrated to dryness. The combined solids were treated with an aqueous potassium hydroxide solution $(20 \mathrm{~g}$ of $\mathrm{KOH}$ and $120 \mathrm{ml}$ of water). The aqueous mixture was extracted with ether $(140 \mathrm{ml} \times 1$ and then $70 \mathrm{ml} \times 4)$. The combined ether solutions were washed with $2 \%$ potassium carbonate solution $(40 \mathrm{ml} \times 4)$ and dried on potassium carbonate. The solvent was then removed and the residue distilled under reduced pressure $\left(72-73^{\circ} \mathrm{C} / 3 \mathrm{mmHg}\right)$. Yield, $7.1 \mathrm{~g}\left(76^{\circ} \%\right)$.

\section{$N$-p-Vinylbenzyl-D-gluconamide (1)}

Commercial D-glucono-1,5-lactone $\quad(7.25 \mathrm{~g}$, $40.7 \mathrm{mmol})$ was dissolved in methanol $(250 \mathrm{ml})$ by gentle heating followed by the addition of $p$ vinylbenzylamine $(5.43 \mathrm{~g}, 40.8 \mathrm{mmol})$ in methanol $(50 \mathrm{ml})$, and the mixture was heated under reflux for $90 \mathrm{~min}$. A white crystalline precipitate started to separate in $10 \mathrm{~min}$. The precipitate was filtered, washed with cold methanol, and dried in vacuo. Yield, $11.7 \mathrm{~g}(92.4 \%)$. Recrystallization from methanol gave 1 in the form of plates. $\mathrm{mp} 184^{\circ} \mathrm{C}$ (dec.); $[\alpha]_{D}^{25}+31.2^{\circ}$ (cl in $\mathrm{Me}_{2} \mathrm{SO}$ ). Calcd for $\mathrm{C}_{15} \mathrm{H}_{21} \mathrm{NO}_{6}$ : C, $57.87 \%$; H, $6.80 \%$; N, $4.50 \%$. Found: C, $57.95 \%$; $\mathrm{H}, 6.80 \%$; N, $4.45 \% .{ }^{13} \mathrm{C}$ NMR ( $\left.\mathrm{Me}_{2} \mathrm{SO}-d_{6}, \mathrm{TMS}\right)$, $\delta 172.09=\mathrm{C}=\mathrm{O}, 138.96$ phenyl (para: the root of benzyl methylene), $136.04=\underline{\mathrm{C}}=\mathrm{CH}_{2}, 135.12$ phenyl (the root of vinyl), 127.00 and 125.54 phenyl (meta and ortho), $113.33=\mathrm{CH}_{2}, 73.54,72.23$, 71.26, and $69.85 \mathrm{C}(2)-\mathrm{C}(5), 63.09 \mathrm{C}(6), 41.34$ benzyl methylene.

\section{Polymerization}

A mixed solution of the monomer $\mathbf{1}$, azobis(isobutyronitrile) (AIBN), and $\mathrm{Me}_{2} \mathrm{SO}$ was charged in a glass ampule, frozen in a solid carbon dioxidemethanol bath, and degassed three times. The ampule was sealed under reduced pressure and 
maintained in a thermostat at $60 \pm 0.05^{\circ} \mathrm{C}$. The solution was chilled and poured into cold methanol. The polymer was reprecipitated from its $\mathrm{Me}_{2} \mathrm{SO}$ solution into methanol four times and freeze-dried from its aqueous solution. Calcd for $\left(\mathrm{C}_{15} \mathrm{H}_{21} \mathrm{NO}_{6}\right)_{n}$ : C, $57.87 \%$; H, $6.80 \%$; N $4.50 \%$. Found: C, 58.06\%; $\mathrm{H}, 6.83 \%$; N, $4.41 \% .{ }^{13} \mathrm{C}$ NMR ( $\mathrm{Me}_{2} \mathrm{SO}-d_{6}$, TMS) $\delta 172.04 \wedge \mathrm{C}=\mathrm{O}, 143.29$ and 142.66 phenyl (the root of main chain), 135.95 phenyl (the root of benzyl methylene), 126.56 phenyl (ortho and meta), $73.54,72.47,71.50$, and $70.14 \mathrm{C}(2)-\mathrm{C}(5)$, and 63.23 $\mathrm{C}(6)$.

\section{RESULTS AND DISCUSSION}

\section{Synthesis and Polymerization of N-p-Vinylbenzyl-D- gluconamide (1)}

The coupling reaction of $p$-vinylbenzylamine with D-glucono-1,5-lactone was fast and the crystalline product precipitated quantitatively during the reaction. Monomer 1 was soluble in $\mathrm{Me}_{2} \mathrm{SO}, \mathrm{DMF}$, and pyridine at room temperature, and in water, methanol, and diethyleneglycol at $60^{\circ} \mathrm{C}$, but insoluble in such solvents as glycerol and acetonitrile.

Polymerization was carried out with AIBN as the initiator in $\mathrm{Me}_{2} \mathrm{SO}$ at $60^{\circ} \mathrm{C}$ as summarized in Table I. The polymerization proceeded homogeneously. It was terminated at a moderate conversion. The white powdery polymer obtained was soluble in water, glycerol, $\mathrm{Me}_{2} \mathrm{SO}, \mathrm{DMF}$, and pyridine, but insoluble in methanol, acetone, and acetonitrile. The solubility of the polymer in water and glycerol was higher than that of the monomer. We assumed that the intermolecular interaction through hydrogen bonds among amide and hydroxyl groups was strong in the monomer molecules. The formation of the polymer backbone disordered the hydrogen bonds, thus increasing the solubility in protic solvents.

The intrinsic viscosities determined in $\mathrm{Me}_{2} \mathrm{SO}$ were high, suggesting these polymers to be of high molecular weight. The intrinsic viscosities in water were about one third those in $\mathrm{Me}_{2} \mathrm{SO}$. The low viscosity reflected a tightly-coiled conformation of $\mathbf{2}$ in water. Conformation in water was also shown by ${ }^{1} \mathrm{H}$ and ${ }^{13} \mathrm{C}$ NMR spectra measured in $\mathrm{Me}_{2} \mathrm{SO}-d_{6}$ and deuterium oxide. In the latter solvent, the signals were observed to broaden, particularly the phenyl signals $\left(\delta 145,136\right.$, and $128 \mathrm{ppm}$ in ${ }^{13} \mathrm{C}$ NMR and $\delta \sim 7 \mathrm{ppm}$ in $\left.{ }^{1} \mathrm{H}-\mathrm{NMR}\right)$. This broadening was probably due to intense stacking of phenyl
Table I. Polymerization of $N$-p-vinylbenzylD-gluconamide (1)

\begin{tabular}{|c|c|c|c|c|c|}
\hline 1 & AIBN & Yield & {$[\alpha]_{\mathrm{D}}^{25 \mathrm{~b}}$} & {$[\eta]^{\mathrm{c}}$} & \\
\hline $\mathrm{g}$ & $\mathrm{mol}^{\circ} \%$ to 1 & $\%$ & deg & In $\mathrm{Me}_{2} \mathrm{SOIn}$ & n water \\
\hline 2.49 & 0.5 & 58 & +37.9 & 1.27 & 0.42 \\
\hline 2.49 & 0.25 & 44 & +37.3 & 1.60 & 0.47 \\
\hline
\end{tabular}

${ }^{\text {a }} \mathrm{Me}_{2} \mathrm{SO}, 5 \mathrm{ml}$; temp, $60^{\circ} \mathrm{C}$; time, $4.5 \mathrm{~h}$.

b $1 \mathrm{~g} / 100 \mathrm{ml}$ in $\mathrm{Me}_{2} \mathrm{SO}$.

c At $25^{\circ} \mathrm{C} ; c, \mathrm{~g} / 100 \mathrm{ml}$.

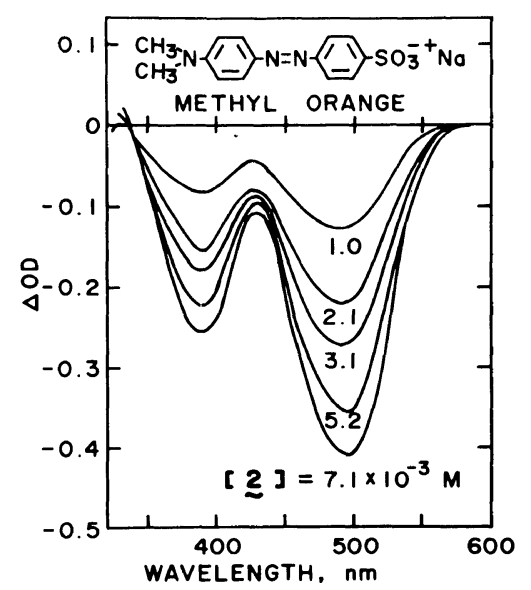

Figure 1. Difference absorption spectra of methyl orange in the presence of polymer 2 . [MO], $1 \times 10^{-4} \mathrm{M}$.

groups and the small mobility of the main chains in water.

Flexible membranes could be cast from a $\mathrm{Me}_{2} \mathrm{SO}$ solution, but those cast from an aqueous solution were brittle.

Binding of Methyl Orange and Magnesium 1Anilino-8-naphthalenesulfonate (ANS) to Amphiphilic Polymer 2 in Water

Difference absorption spectra of the methyl orange solutions in the absence and presence of polymer 2 are shown in Figure 1. An isosbestic point was observed at $340 \mathrm{~nm}$, indicating that there exist free and bound methyl orange species. According to the treatment previously described, ${ }^{3}$ difference optical density $(\Delta \mathrm{OD})$ can be expressed by eq 1 .

$$
\Delta \mathrm{OD}=[\mathrm{MO}]_{\mathrm{B}} \varepsilon
$$


Table II. Binding of methyl orange and magnesium 1-anilino-8-naphthalenesulfonate (ANS) to polymers $\mathbf{2}$ and $\mathbf{3}$

\begin{tabular}{|c|c|c|c|c|c|c|}
\hline \multirow{2}{*}{ Solute } & \multirow{2}{*}{ Polymer } & $\lambda_{\mathrm{B}, \max }{ }^{\mathrm{a}}$ or $\lambda_{\mathrm{B}, \max }^{\mathrm{F}}{ }^{\mathrm{b}}$ & \multirow{2}{*}{$\begin{array}{c}\varepsilon_{\mathrm{B}, \max }{ }^{\mathrm{c}} \text { or } \\
I_{\infty} / I_{0}{ }^{\mathrm{d}}\end{array}$} & \multirow{2}{*}{$\frac{K^{\prime \mathrm{e}}}{\mathrm{M}^{-1}}$} & \multirow{2}{*}{$\frac{K n^{\mathrm{f}}}{\mathrm{M}^{-1}}$} & \multirow{2}{*}{$1 / n^{\varepsilon}$} \\
\hline & & $\mathrm{nm}$ & & & & \\
\hline Methyl orange & 2 & $450^{a}$ & $21000^{c}$ & 220 & 220 & $\sim 1$ \\
\hline Methyl orange & 3 & $445^{\mathrm{a}}$ & $21300^{c}$ & 80 & 90 & 20 \\
\hline ANS & 2 & $477^{\mathrm{b}}$ & $360^{\mathrm{b}}$ & 120 & 110 & $\sim 1$ \\
\hline ANS & 3 & $475^{\mathrm{b}}$ & $125^{\mathrm{d}}$ & 120 & 130 & 20 \\
\hline
\end{tabular}

a Wavelength of the absorption maximum of the bound methyl orange.

b Wavelength of the fluorescence maximum of the bound ANS.

c Molar absorbance of the bound methyl orange.

d Relative fluorescence intensity of the bound ANS.

e Binding constant of the Benesi-Hildebrand relationship based on a structural unit.

${ }^{f}$ Binding constant of the Klotz relationship based on a structural unit.

$\mathrm{g}$ Minimum number of structural units required to bind a solute molecule.

$$
\begin{aligned}
{[\mathrm{MO}] } & =[\mathrm{MO}]_{\mathrm{B}}+[\mathrm{MO}]_{\mathrm{F}} \\
\varepsilon & =\varepsilon_{\mathrm{B}}-\varepsilon_{\mathrm{F}}
\end{aligned}
$$

In these equations, $[\mathrm{MO}]_{\mathrm{B}},[\mathrm{MO}]_{\mathrm{F}}$, and $[\mathrm{MO}]$ stand for the concentration of the bound, free, and total methyl orange species, and $\varepsilon_{\mathrm{B}}$ and $\varepsilon_{\mathrm{F}}$, for the molar absorbance of the bound and free methyl orange species, respectively.

Plots of the Benesi-Hildebrand relationship ${ }^{7}$ (eq 4) using $\triangle \mathrm{OD}$ at $495 \mathrm{~nm}$ yielded a straight line.

$$
\frac{[\mathrm{MO}]}{\Delta \mathrm{OD}}=\frac{1}{[2]} \times \frac{1}{K^{\prime} \varepsilon}+\frac{1}{\varepsilon}
$$

The binding constant $K^{\prime}$ was calculated from the slope to be $220 \mathrm{M}^{-1}$. From the intercept, $\varepsilon$, and then $[\mathrm{MO}]_{\mathrm{B}}$ and $\varepsilon_{\mathrm{B}}$ were obtained. Estimation of $\varepsilon_{\mathrm{B}}$ at various wavelengths led to an assumed absorption spectrum of the bound methyl orange species. The spectrum had $\lambda_{\mathrm{B} \text {, max }}$ at $450 \mathrm{~nm}\left(\varepsilon_{\mathrm{B}, \max }, 21000\right)$, which was blue-shifted by about $20 \mathrm{~nm}$ from that of the free methyl orange $\left(\lambda_{\mathrm{F}, \max }, 464 \mathrm{~nm} ; \varepsilon_{\mathrm{F}, \max }, 25100\right)$. The blue-shift suggests that the bound methyl orange remained in a hydrophobic microenvironment. $^{8}$ Plots of the Klotz relationship ${ }^{9}$ (eq 5) also gave a straight line.

$$
\frac{[2]}{[\mathrm{MO}]_{\mathrm{B}}}=\frac{1}{[\mathrm{MO}]_{\mathrm{F}}} \times \frac{1}{K n}+\frac{1}{n}
$$

The first binding constant $K n$ was $220 \mathrm{M}^{-1}$, and the constant $1 / n$ was about 1 . These binding properties are summarized in Table II, along with the data of 3.
The interaction of 2 with ANS, a hydrophobic fluorescence probe, was investigated by spectrofluorometry. The excitation wavelength used was 380 $\mathrm{nm}$. The fluorescence of ANS alone, $\left(\lambda_{\mathrm{F}, \max }^{\mathrm{F}}, 525 \mathrm{~nm}\right)$, was negligible, but polymer 2 enhanced the fluorescence strikingly and blue-shifted the emission maximum $\left(\lambda_{\mathrm{B}, \max }^{\mathrm{F}}\right)$ to $477 \mathrm{~nm}$. The blue-shift by $45 \mathrm{~nm}$ indicates an apolar microenvironment of the bound ANS. ${ }^{10}$ Binding constants were estimated from the corresponding Benesi-Hildebrand and Klotz relationships and are listed in Table II.

The strong affinity of polymer $\mathbf{2}$ for the organic solutes has thus been demonstrated. However, polymer $\mathbf{2}$ as well as polymer $\mathbf{3}$ carry no specific binding sites such as the charged groups, long alkyl chains, inclusion cavities, and cross linkings. In addition, monomer 1 exhibited no binding properties. The viscosities and NMR spectra suggested that, in water, polymer 2 was in a tightly-coiled conformation and the mobility of the styrene backbone was restricted. Therefore, we assumed the binding ability of $\mathbf{2}$ and $\mathbf{3}$ to be attributable to the polymer conformation induced by the amphiphilic structures. The vinylbenzyl residues aggregated to form hydrophobic regions surrounded by hydrated sugar residues. Organic solutes were held strongly in the hydrophobic regions in a micelle-like conformation.

The binding properties of 2 and 3 can be compared from the data in Table II. The similarity of the blue shifts suggests that the binding sites of both polymers had about the same hydrophobicity. The 
term $1 / n$, the minimum number of structural units required to bind a solute molecule, of 2 was different from that of $\mathbf{3}$. The binding constant of $\mathbf{2}$ with methyl orange was about twice those of other combinations. These similarities and differences in the binding of $\mathbf{2}$ and $\mathbf{3}$ might arise from the structural features pointed out in the Introductory Section.

In summary, Scheme 1 presents a convenient, high yield procedure for synthesizing a special polymer containing a pendant carbohydrate, and polymer $\mathbf{2}$ caused organic solutes to bind strongly to its micelle-like hydrophobic regions in water.

Acknowledgements. The authors thank Prof. Mikio Takaki for his helpful advice in making the synthesis of $p$-vinylbenzylamine.

\section{REFERENCES}

1. T. J. Williams, N. R. Plessas, and I. J. Goldstein, Carbohydr. Res., 67, C1 (1978).

2. T. J. Willimas, N. R. Plessas, and I. J. Goldstein, Arch. Biochem. Biophys., 195, 145 (1979).

3. K. Kobayashi and H. Sumitomo, Macromolecules, 13, 234 (1980).

4. K. Kobayashi and H. Sumitomo, Polym. J., 13, 517 (1981).

5. K. Kobayashi, H. Sumitomo, and Y. Ina, Kobunshi Ronbunshu, 39, 723 (1982).

6. T. Miyake and S. Tanimoto, Yukigoseikagaku, 31, 1050 (1973).

7. H. A. Benesi and J. H. Hildebrand, J. Am. Chem. Soc., 71, 2703 (1949).

8. I. M. Klotz and K. Shikama, Arch. Biochem. Biophys., 123, 551 (1968).

9. I. M. Klotz, F. M. Walker, and R. B. Pivan, J. Am. Chem. Soc., 68, 1486 (1946).

10. L. Stryer, J. Mol. Biol., 13, 482 (1965). 